Table 1

\begin{tabular}{|c|c|c|c|}
\hline Fish & $\begin{array}{l}\text { xantho- } \\
\text { pterin }\end{array}$ & $\begin{array}{l}\text { ichthyo- } \\
\text { pterin }\end{array}$ & $\begin{array}{l}\text { isoxantho- } \\
\text { pterin }\end{array}$ \\
\hline 1. Cyprinus carpio & + & + & + \\
\hline 2. Tilapia Mossambica & + & + & - \\
\hline 3. Puntius javanicus . . . . & - & + & + \\
\hline 4. Osteochilus kasselti . . . & - & + & -. \\
\hline 5. Trichochaster trichopterus & + & - & + \\
\hline 6. Trichochaster pertoralis . & + & - & + \\
\hline 7. Monopterus albus . . . & - & - & $-*$ \\
\hline 8. Helostoma temmincki. . & - & + & - \\
\hline 9. Osphronemus goramy . . & t & - & + \\
\hline 10. Chanos chanos.... & + & + & - \\
\hline
\end{tabular}

*) Green fluorescent spot.

Indonesian names: 1. Ikan mas; 2. Mudjair; 3. Tawes; 4. Nilam; 5. Sepatdjawa; 6. Sepat siam; 7. Belut; 8. Tambakan; 9. Gorami; 10. Bandeng.

paper chromatography. The chromatograms are deveioped with $3 \% \mathrm{NH}_{4} \mathrm{Cl}$ solution, and butanol-5 $\mathrm{n}$ acetic acid, 2:1, and the spots viewed under ultra violet light $(254 \mathrm{~m} \mu)$.

For identification of the spots, $R_{F}$ values were measured, and compared with the spots of a sample of pure xanthopterin and ichthyopterin we had at our disposal.

The results are found in the table 1. Bogor

Laboratory for Organic Chemistry, University of Indonesia,

Eingegangen am 29. März 1958

A. Dupont

\section{Zur Frage der Identität von menschlichen Spermaplasmaproteinen und Serumeiweißen}

Es wurde mehrfach nachgewiesen, daß sich die Eiweiße des Spermaplasmas (SP) ebenso wie die Serumproteine elektrophoretisch in mehrere Fraktionen auftrennen lassen. Die makroelektrophoretischen Untersuchungen von GRAY und HugGINs ${ }^{2}$ ), Ross, MoOre und MILLER ${ }^{6}$ ) sowie die papierelektrophoretischen (PE) Untersuchungen von OBÉ und HermanN ${ }^{4}$ ), SchNeIDER, Nowakowski und Vorgt ${ }^{7}$ ) und KEUTEr und $\mathrm{GABSCH}^{3}$ ) erbrachten weder ïber die Zahl der Fraktionen noch ubber die Bezeichnung der einzelnen Gipfel und ihre Zuordnung übereinstimmende Ergebnisse. Ross ${ }^{5}$ ) hatte gezeigt daß sich durch Injektion von Human-SP beim Kaninchen Antikörper gegen Serumalbumin erzeugen lassen, jedoch konnte er die SP-Albumine in den Elektrophoresekurven nicht eindeutig einordnen.

Zur Klärung der in der Literatur viel diskutierten Frage der Identität von Serum- und SP-Eiweißkörpern erschien uns die Immunelektrophorese ${ }^{1}$, welche die Kombination von Elektrophorese und der streng spezifischen Präzipitinrealition in einem Arbeitsgang ermöglicht, geeignet.

Methodik: Nach den vorbereitenden Arbeiten zur Gewinnung spermienfreien SP's (Dauer $90 \mathrm{~min}$ ) wurde im AgarGel in Veronal-Salzsäurepuffer $\left(\mathrm{PH}_{\mathrm{H}}=8,2 ; \mathrm{T} / 2=0,05\right)$ während 3 Std bei etwa $60 \mathrm{~mA}$ und $120 \mathrm{~V}$ aufgetrennt. Färbung mit Amidoschwarz oder Azokarmin in wäßriger Lösung. Aus seitlich gezogenen Gräben lieB man nach Auftrennung der Fraktionen Antihumanserum vom Pferd (Institut Pasteur, Paris) mehrere Tage bis $z u 3$ Wochen eindiffundieren. Das Mengenverhältnis von Antigen-Antikörpern wurde weitgehend variiert.

Evgebnisse: a) Agarelektrophorese. In frischem SP sind im allgemeinen 8 , nach $32-$ bis 48 stündigem Stehenlassen des SP bei $4^{\circ} \mathrm{C}$ bis $z u 10$ Fraktionen darstellbar, die viel deutlicher als bei der PE abgegrenzt sind. Eine Fraktion wandert konstant gleich schnell wie Serumalbumin. Anodenwärts davor liegt eine Vorfraktion (o). Im Gammabereich liegen meist 3 Fraktionen, die sich nach Stehenlassen des SP anscheinend verändern, da sie sich weiter auftrennen und teilweise, auch unter Berücksichtigung der Elektroendosmose, weiter als die Gammaglobuline kathodisch wandern.

b) Immznoelektrophorese. Nur die mit gleicher Geschwindigkeit wie die Serumalbumine wandernde Fraktion wird konstant im Kreuzversuch mit Antihumanserum deutlich ausgefällt. Sie ist also auch immunologisch mit Serumalbumin identisch und wäre demnach mit $A$ zu bezeichnen. Präzipitationsringe im Bereich der mit Serum-Alpha- und Betaglobulinen gleich schnell wandernden SP-Eiweiße waren teils inkonstant, teils unscharf. Diese Fraktionen sind offenbar nicht einheitlich, Teilfraktionen könnten mit Serumglobulinen identisch sein.
P 5, P 6, P 7 (vgl. Fig. 1) liegen - gut angefärbt - im Gammabereich. Die bei der Ultrafiltration ins Filtrat gehenden Proteosen liegen nach Elektrophorese ebenfalls in diesem Bereich (vgl. P 1 von Ross et al.). Der weit überwiegende Anteil von P 5, P 6, P 7 dürfte also aus Proteosen bestehen,

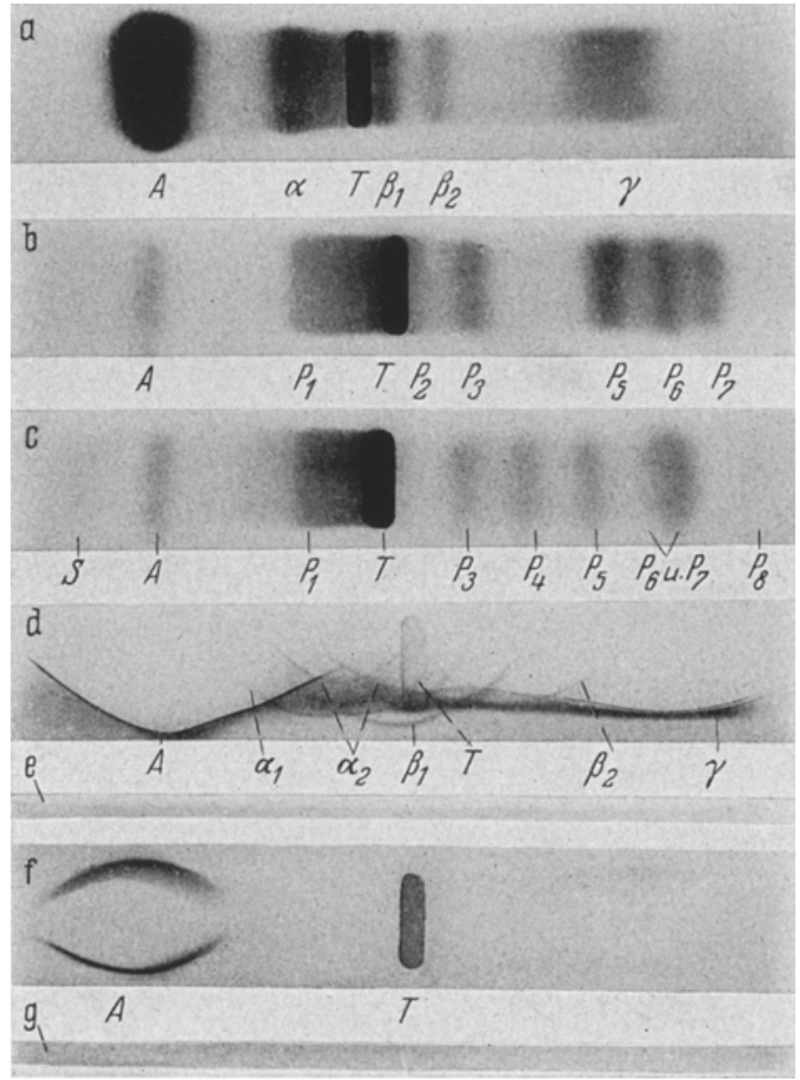

Fig. 1. Elektrophorese. a Normaiserum. Mit Amidoschwarz gefärbt. $b 0,03 \mathrm{~cm}^{3} \mathrm{SP}, 90 \mathrm{~min}$ nach Gewinnung getrennt. $c 0,02 \mathrm{~cm}^{3}$ $\mathrm{SP}, 30 \mathrm{Std}$ nach Gewinnung getrennt. Immunoelektrophorese: d $0,03 \mathrm{~cm}^{3}$ Normalserum. Präzipitate mit Azokarmin gefärbt. Aus dem Graben $e$ ist Pferdeantihumanserum $(1: 2$ verdünnt $)$ eindiffundiert. Die Präzipitationslinien sind gut zu erkennen. $10,05 \mathrm{~cm}^{3} \mathrm{SP}$. ungefärbt. Von $e$ nach $f$ diffundierte Pferdeantihumanserum $1: 2$ verdünnt, von $g$ nach $f 1: 5$ verdünnt. Eine Albuminlinie ist wegen Antikörperüberschuß verwaschen, die andere Linie angedeutet gedoppelt. Im $y$-Bereich ganz geringe, verwaschene Präzipitationen. Methodik im Text. $T$ Auftragestelle

die mit den Serumgammaglobulinen nicht identisch sind, da bei der Immunoelektrophorese nur selten eine schwache, verwaschene Präzipitation im Gammabereich auftritt.

Urologische Universitätsklinik (Direktor: Prof. Dr. C. E ALKEN) und Institut für Hygiene und Mikrobiologie dev Universität des Saarlandes (komm. Leiter: Priv.-Doz. Dr. G. W. FISCHER), Homburg/Saar

G. Hermann, W. Licht, H. J. KeUtel und E. Krug

Eingegangen am 22. Februar 1958

1) Grabar, P., u. C.A. Williams: Biochem. Biophys. Acta 17, 67 (1955). - 2) Gray, S., u. C. Huggins: Proc. Soc. Exp. Biol. a. $\left.67(1955) .-{ }^{2}\right)$ Gray, S., u. C. HugGins: Proc. Soc. Exp. Biol. a. Med. 50, 351 (1942). - 3) Keutel, H. J., U. H. Ch. Gabsch: Im
Druck. - ${ }^{\text {) }}$ Obś, G., u. G. Hermann: Z. Urol. 47, 393 (1954). 5) Ross, V.: J. Immunology 52, 87 (1946). - 6) Ross, V., D.H. MOORE u. E.G. Miller: J. of Biol. Chem. 144, 667 (1942). 7) SCHNeIDER, W., H. Nowakowski u. K.D. VoIgt: Klin. Wschr. $1954,863$.

\section{Untersuchungen über die Heterogenität und Organspezifität von Enzymen, speziell der Milchsäuredehydrogenase, innerhalb der Wirbeltierreihe}

Th. Wieland und G. Pfleiderer ${ }^{1}$ ), ${ }^{2}$ ) haben erstmalig bei Säugetieren gezeigt, daß die Milchsäuredehydrogenase eines Organs innerhalb verschiedener Ordnungen verschieden ist sowie daß die Organe eines Tieres verschiedene Milchsäuredehydrogenasen besitzen. Es sollte daraufhin eine systematische Untersuchung dieses Ferments innerhalb der Wirbeltiere durchgeführt werden. 